\title{
BMJ Open Appreciative inquiry in evaluating integrated primary oral health services in Quebec Cree communities: a qualitative multiple case study
}

\author{
Richa Shrivastava, ${ }^{1}$ Yves Couturier, ${ }^{2}$ Felix Girard, ${ }^{1}$ Christophe Bedos, ${ }^{3}$ \\ Mary Ellen Macdonald, ${ }^{3}$ Jill Torrie, ${ }^{4}$ Elham Emami (D) ${ }^{3}$
}

To cite: Shrivastava R, Couturier Y, Girard F, et al. Appreciative inquiry in evaluating integrated primary oral health services in Quebec Cree communities: a qualitative multiple case study. BMJ Open 2020;10:e038164. doi:10.1136/ bmjopen-2020-038164

- Prepublication history and additional material for this paper are available online. To view these files, please visit the journal online (http://dx.doi org/10.1136/bmjopen-2020038164).

Received 29 February 2020 Revised 20 May 2020 Accepted 21 May 2020

Check for updates

C Author(s) (or their employer(s)) 2020. Re-use permitted under CC BY-NC. No commercial re-use. See rights and permissions. Published by BMJ.

${ }^{1}$ Faculty of Dentistry, Université de Montréal, Montréal, Québec, Canada

${ }^{2}$ School of Social Work, Université de Sherbrooke, Sherbrooke, Québec, Canada ${ }^{3}$ Faculty of Dentistry, McGill University, Montréal, Québec, Canada

${ }^{4}$ Public-Health Department, Cree Board of Health and Social Services of James Bay, Mistissini, Québec, Canada

Correspondence to

Dr Elham Emami;

elham.emami@mcgill.ca

\section{ABSTRACT}

Objective The Strategic Regional Plan of the Cree Board of Health and Social Services of James Bay (CBHSSJB), serving the Quebec Cree communities, mandates the objective of integrating oral health within primary healthcare. Emerging evidence suggests that the integration of oral health into primary healthcare can decrease oral health disparities. This research study aimed to answer the following research question: how and to what extent does the integration of oral health into primary healthcare address the oral health needs of the Cree communities?

Design We used a multiple-case study design within a qualitative approach and developmental evaluation methodology. The Discovery, Dream, Design and Destiny model of appreciative inquiry was selected as a study framework among existing frameworks of the developmental evaluation.

Setting Four purposefully selected Cree communities. Participants Healthcare providers, administrators and patients at the community wellness centres and hospital.

Outcome measures Integration of oral health into primary healthcare.

Results A total of 36 interviews and 6 focus group discussions were conducted. We identified ten themes in discovery and dream phases. The Discovery phase identified the strengths of the organisation in facilitating enablers of integration including strategic planning, organisational structure, cultural integration, coordinated networks and colocation. In the Dream phase, participants' oral healthcare stories expressed various dimensions of integration and their wish for strengthening integration via extending public oral healthcare programmes, increasing resources and improving organisational management. In the Design phase, recommendations were formulated for a future action plan within the CBHSSJB.

Conclusion This study results suggested that the CBHSSJB has been successful in implementing oral health integration into primary care following its strategic planning. At present, the organisation could extend the level of integration into full integration by following study recommendations derived from the perspective of local stakeholders.
Strengths and limitations of this study

- Appreciative inquiry is, for the first time, used in the field of indigenous oral health research that allows better recognition of Indigenous culture and values in organisational health services.

- The multiple-case study design helped to gain insight into the integration of dental services into primary healthcare services in Cree communities and enabled the Indigenous participants to enunciate their experiences from a holistic perspective.

- The trustworthiness of the study was ensured through member checking and triangulation of multiple methods, data sources and investigators

- This evaluation research could be instrumental in developing evidence on optimal implementation of integrated primary oral healthcare model in other similar communities/settings.

- This study might have encountered bias due to various types of study participants such as administrators, healthcare providers and patients.

\section{INTRODUCTION}

Indigenous communities experience a substantially greater extent of oral health disparities than the general population. ${ }^{1-4}$ These disparities are associated with a broad range of social determinants at proximal (such as health and oral health behaviour, education, income), intermediate (health and oral healthcare systems, educational system, cultural continuity) and distal (colonialism, racism and social exclusion) levels. ${ }^{5}$ The oral health disparities within this complex intersection and interrelation of health determinants need to be broadly tackled by systemfocused collaborative approaches such as an integrated care approach. ${ }^{6}$ Therefore, the integration of oral healthcare within primary health has been proposed as a strategy for addressing oral health disparities. ${ }^{78}$

Integrated care is defined as 'a coherent and coordinated set of services which are 
planned, managed and delivered to individual service users across a range of organisations and by a range of cooperating professionals and informal carers'. ${ }^{9}$ Primary oral healthcare (POHC) is defined as 'the integration of services that promote and preserve oral health, prevent oral disease, injury and dysfunction and provide a regular source of care for acute and chronic oral diseases and disabilities'. ${ }^{10}$

The Cree Board of Health and Social Services of James Bay (CBHSSJB), as a pioneer in the Canadian province of Quebec, implemented a model for the integrated delivery of health and social services that includes primary oral healthcare. ${ }^{11} 12$ This organisation is responsible for providing health and social services to the Crees of Northern Quebec. ${ }^{11}$ 'Eeyou Istchee' (the land of the people) is the homeland of the Crees of Northern Quebec who live in nine communities with a total population of over $18000 .{ }^{13}$ The CBHSSJB's Strategic Regional Plans 2004-2014 and 2016-2021 mandated a model for the integrated delivery of health and social services in the Cree communities. Henceforth, the integration of oral health within primary healthcare was one of the specific objectives of this strategic planning. ${ }^{11} 14$

Available evidence indicates the gap in knowledge about integrated oral healthcare programmes and their outcomes and supports performing evaluation research to create evidence-based data on this topic. ${ }^{15}$ Therefore, this study was conducted in collaboration with the CBHSSJB to evaluate its integrated POHC programme.

The research question was: how and to what extent does the integration of oral health into primary care address the oral health needs of the Cree communities? Based on an appreciative inquiry (AI) approach, ${ }^{16}$ the study objectives were to (1) Discover the strengths of the CBHSSJB's oral healthcare policies in the integration of services; (2) Explore the Cree communities' members' oral-health experiences and their dreams for oral care services and (3) Develop recommendations to support planned actions within the communities.

\section{METHODS}

The study is part of a larger Canadian Institutes of Health Research funded project on Oral Health Integration into Primary Care. ${ }^{17}$ We followed the Standards for Reporting Qualitative Research guideline for reporting qualitative studies for writing this manuscript. ${ }^{18}$ This study was performed in compliance with the ethical guidelines of Ownership, Control, Access and Possession for First Nations. ${ }^{19}$

\section{Study setting}

We purposefully selected four Cree communities based on the identification of diverse characteristics such as demography, geography, culture and oral healthcare. Each of the nine Cree communities has a Community Miyupimaatisiiun (wellness) Centre (CMC).$^{20}{ }^{21}$ These centres offer a wide variety of health services including

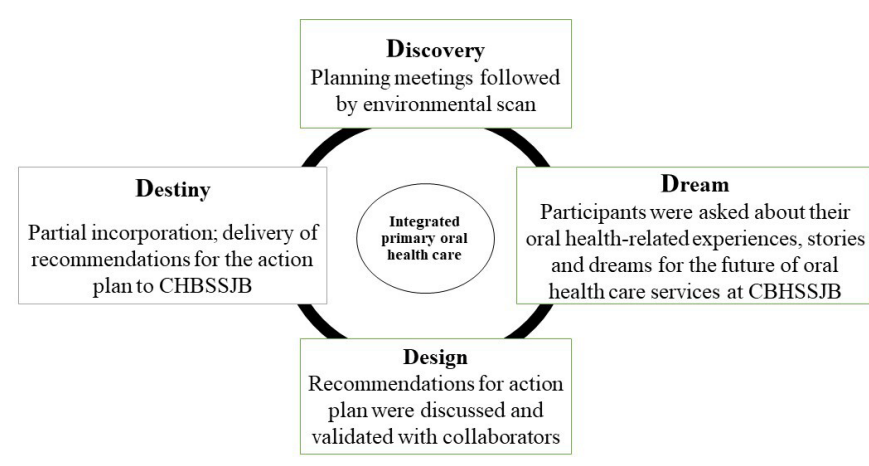

Figure 1 Study phases as per Al's 4 D model. Al, appreciative inquiry; CBHSSJB, Cree Board of Health and Social Services of James Bay; 4 D, Discovery, Dream, Design and Destiny.

dentistry. ${ }^{20} 21$ The CHBSSJB also operates one regional hospital, a regional public health department, homes for troubled youths, Cree Patient Services (Wiichihiituwin) liaison offices as well as human resources recruitment office. $^{21}$

\section{Study design}

We used a multiple-case study design within a qualitative approach and developmental evaluation methodology. ${ }^{22} 23$ A case study is the most common design used in evaluation research that helps in examining contemporary phenomena in real-life situations. ${ }^{22}$ Developmental evaluation is useful in adapting an intervention under complex conditions such as health system issues in culturally diverse contexts, where influences from multiple factors make it difficult to anticipate what will happen as the intervention progresses. ${ }^{23} 24$

Among various frameworks of developmental evaluation, we selected AI. AI is a philosophical, cooperative and systematic approach for transformational change that searches for 'what gives life' to the organisation, recognises the best in individuals, organisations and the world around them to create a better future ${ }^{25}{ }^{26}$ We selected AI because it is a success focused, culturally responsive and cost-effective framework that encompasses the diverse perspectives and experiences of the stakeholders. ${ }^{27}$ The four phases of AI's Discovery, Dream, Design and Destiny model guided this project as illustrated in figure $1 .^{16}$

\section{Study phases}

\section{Discovery}

This phase included planning meetings followed by an environmental scan. The planning meetings were conducted in the form of a workshop and videoconference that involved several activities such as presentations, focus group discussions (FGD) and interviews. ${ }^{12}$ They engaged representatives of Cree community members, health and oral healthcare service providers and administrators to solicit their feedback and to facilitate the development of agreement and community consensus on the project evaluation plan. ${ }^{16}$ Various evaluation models were also discussed with these stakeholders, and they selected 
the Five foundations of integrated $\operatorname{car}^{28}$ as a model for this project evaluation.

The planning meetings were followed by an environmental scan. It comprised observations of four CMCs and a documentation review. The documents were obtained from identified key collaborators and the CBHSSJB website. The environmental scan helped in retrieving background information and clarifying purposes, rationale, historical insight and the most recent information related to the oral health policies at the CBHSSJB. ${ }^{29}$

\section{Dream}

Key stakeholders such as administrators, health and oral healthcare providers and patients at the community Miyupimaatisiiun centres and hospital were asked about their oral health-related experiences, stories and dreams for the future of oral healthcare services at the CBHSSJB during FGD and individual interviews. ${ }^{16}$

\section{Design}

This phase involved formulating recommendations for deploying the 'dreamed' oral healthcare at CBHSSJB. ${ }^{16}$ The results and recommendations realised through the previous phases were discussed and validated for the stakeholders' review, acceptance and confirmation during various CHBSSJB official meetings and precisely planned meetings.

\section{Destiny}

This phase was partially incorporated since it included the delivery of recommendations for the action plan to the CBHSSJB in the form of lay and scientific reports.

\section{Sampling and data collection}

Maximum variation sampling and snowball techniques were used to identify and recruit participants for data collection. ${ }^{30}$ Cree community partners at CBHSSJB helped in selecting potential participants, including administrators, care providers and patients. The maximum variation sampling allowed the emergence of diverse viewpoints. Through snowball sampling, selected participants recommended other potential candidates for the study. ${ }^{30}$ The data collection included the environmental scan, FGD and individual in-depth interviews. FGD and individual interviews were conducted in English or French by two research team members trained in qualitative methods. Data collection continued until saturation was achieved. ${ }^{30}$ The semistructured interview guide was developed based on the Rainbow model of integrated care and AI, which was tailored based on the participants' profiles (online supplementary file 1). ${ }^{27} 31$ Accordingly, based on the Rainbow model, we included questions on each dimension of integration, and based on AI, we involved questions focusing on successful processes and outcomes of integration. $^{27} 31$ The interviews, on average $40 \mathrm{~min}$ in length, and FGD, on average 1 hour and 15 min in length, were conducted between January 2016 and December 2017 in a quiet room at the Miyupimaatisiiun centres or hospital. They were digitally recorded and transcribed verbatim as text documents.

\section{Data analysis}

The study used the community as the unit of analysis. This research combined the Rainbow model of integrated care and the Five Foundations for Integrated Care model as conceptual frameworks for analysing the data. ${ }^{28}{ }^{31}$ This data analysis was inspired by multiple case study analysis by Yin $^{22}$ and Miles and Huberman. ${ }^{32}$ At first, the data analysis was conducted at the within-case level to explore and describe the findings for each case. This was followed by cross-case analysis to identify similarities and differences across the cases to synthesise the findings and draw conclusions as a whole. ${ }^{32} 33$

Data analysis included transcription, debriefing, codification, data display, thematic content analysis and triangulation. ${ }^{34}$ Raw data were coded and analysed both within and across cases using ATLAS.ti, a qualitative analysis software. Recordings and quotations from collected data were deidentified to ensure the participants' and communities' confidentiality. All transcripts were read and reread, and initial coding was conducted. We developed a coding list based on the coding of the first few transcripts and was discussed with the team members to bolster the consistency of the data interpretation as well as the coding strategy.

Mixed deductive and inductive approaches were used to identify themes. Conceptual frameworks were used to develop themes deductively, whereas new themes from the data were identified inductively. The codes were collapsed to potential themes and final themes via an iterative process by critically analysing concepts and linking them across the data. Word table and matrixes were used to visually examine and synthesise the data for each case and across cases. Any differences in interpretation were resolved by discussion until consensus was achieved (online supplementary file 2 outlines the example of a code tree).

To establish trustworthiness, member checking using synthesised data was done. During member checking, preliminary results were provided to stakeholders, and they were asked to suggest any change or additional information. Other strategies to enhance trustworthiness included the triangulation of multiple data collection methods and data sources as well as investigators triangulation.

\section{Patient and public involvement}

Cree community members participated during the planning phase of the project. Patients were involved in the recruitment and conduct of the study. The research results have been shared with the CHBSSJB organisation to facilitate integrated care in oral health services at this organisation.

\section{RESULTS}

The total number of key participants in Discovery phase was 27 and in Dream phases was 44 (table 1). In total, 6 
Table 1 Total number key informants in Discovery phase and Dream phase

\begin{tabular}{lll}
\hline Phases & & $\begin{array}{l}\text { No of key } \\
\text { informants }\end{array}$ \\
\hline Discovery phase & $\begin{array}{l}\text { Participants in } \\
\text { planning meetings }\end{array}$ & 27 \\
Dream phase & Community 1 & 7 \\
& Community 2 & 20 \\
& Community 3 & 9 \\
& Community 4 & 8 \\
\hline
\end{tabular}

group discussions and 36 interviews were conducted, and ten major themes emerged in the Discovery and Dream phases. For confidentiality purposes, all quotations have been rendered in English.

\section{Discovery phase}

In this phase, from four FGD and three interviews, five themes were identified as strengths of the organisation in integrating oral healthcare.

\section{Theme 1: Cree illustration of the integration}

The concept of integration is embedded in the Cree culture, which promotes working and moving forward interdependently. Working together helped them to claim their rights and sign their land claim agreement 'the James Bay and Northern Quebec Agreement'. Consequently, from a vision of integration, the CBHSSJB developed its first strategic regional plan in 2004 as a tool for integrating health and social services in the Cree communities.

The concept of working together or integrated services is not new to Cree people; we are people who are very interdependent. We believe that in order to move forward, we need each other. And the signing of 'the James Bay Northern Quebec agreement' is one big example of when we achieved working together. (Administrator 1, FGD)

\section{Theme 2: organisation committed to a clear vision}

All the stakeholders appreciated the development of an integrated care delivery model in the CBHSSJB organisation's strategic plans including the integration of oral health. They also valued organisations' continuous efforts in working towards achieving their planned goals and objectives mentioned in their strategic plans.

We're going to make a structure that will be facilitating to bring in the integrated services that have been the vision since 2004-2014. Then, we are working on the strategic plan, then we will look at the objectives that are expected, $[\ldots .$.$] we are working with epidemi-$ ology and statistics. (Administrator 2, FGD)
The CBHSSJB organisation works for integrating oral health by facilitating interprofessional teamwork and oral health promotion during health promotion activities.

There is a connection with dental for a couple of years; [...] people see that oral health is within health in general, ... we had a presentation with diabetes, we have links with the physicians that send us patients ..., we work with the Community Health Representatives (CHR) .... It is the same principle with the school and the daycare... it's part of our goals to integrate within the health field ... but if you look in the south, it's rare for a dental clinic to be inside the hospital. (Dental health care provider 1, FGD)

Theme 3: engaged professionals within an effective organisational structure

Another strength of the CBHSSJB is its multilevel organisational structure under the strong leadership of the board of directors and executive directors. It creates a sound work environment for the professionals to be fully engaged within their roles and responsibilities.

We have the chief of department fully engaging in the administrative duty of the department of the nine clinics, which is very unique. Because of that, we have built up a very good structure. We are closeknit families in between the communities. We often have meetings with the dentists, dental hygienists. (Administrator 3, FGD)

Participants reported that the CBHSSJB has multiple incessant challenges because of the higher prevalence of health problems as well as associated health needs in the communities. Nevertheless, participants praised the organisation's efforts to provide services adapted to the population's local needs.

Local directors in each community... to get a little more local control in adapting the needs of the local communities $[\ldots]$, but how do we work is all together and the patients feel that everything flows well for them. (Administrator 2, FGD)

Theme 4. operational structure that supports integration of oral health

The CBHSSJB has developed an infrastructure facilitating the co-location of the dental clinic with other primary care services. The organisation also provides a supportive environment by providing free basic and referral oral healthcare services.

It's all the relationship, we are in the same building, and we are workers. Now, it's comfortable, we are talking about the nurses, the physicians, for sure physicians could help ... to deal together with them. (Dental care provider 2, FGD) 
Theme 5. significance of Cree language in healthcare provision The importance of the Cree language in the provision of health and oral healthcare was one of the strengths of integrated care delivery at CBHSSJB. The use of Cree language in service delivery promotes Cree traditions and customs. However, translating from English to the Cree language is sometimes difficult due to the unavailability of some scientific terms in the Cree language. Henceforth, this theme pointed out developing and translating the Cree dental terms based on the definition and explanation of the scientific terms.

'Minapidesuu' (the one who pulls teeth out), that's the name of dentist .... So, the fear factor and trauma come back in that word .... So, in order to have the activity of oral dental health care, people take personal responsibility, they won't because of that fear factor in that trauma [...]. I asked better word for oral health care with the CHR for translating for the unilingual speaking or even to children with mothers, they say 'Minapideo' ('to have better-looking teeth'), I say the term 'Minapideo' would be a better term for good oral healthcare. (Administrator 4, FGD)

\section{Environmental scan}

Our results from the documentation review identified five categories of documents from a total of 232 documents, including planning documents, health outcome reports, administrative documents, procedural documents and educational tools. Table 2 outlines environmental scan data on common POHC services in Cree communities. These services include services at CMC, Â Mâshkûpimâtsît Awash, Elementary school-based programmes and Daycare and homecare programmes provided by various dental and non-dental primary healthcare providers. Table 3 provides the contextual description of the four cases and table 4 compares elements of integrated POHC across all four cases.

From the environmental scan, we identified three strengths of the CBHSSJB organisation that support the integration of POHC: (1) provision of dental services proportional to the communities' population; (2) development of strategies for incorporating oral health into service delivery within $\mathrm{CMCs}$ and public health programmes and (3) guidelines for multidisciplinary team working. We also identified the colocation of the dental clinic, the referral system for public programmes and specialised services, and the shared medical record system as facilitators for coordination among care providers. However, some challenges existed in regard to the ill-defined role of general practitioners, the nonoptimal referral procedure and follow-ups within health centres, and the need for more standardised protocols and guidelines.

\section{Dream phase}

A total of two FGD and 33 individual interviews were conducted during this phase and five themes emerged for our analysis.

Theme 1: anticipating the expansion of oral health promotion and faster access to care

Participants shared stories about their satisfaction with the quality of dental services at the clinic. This theme also confirmed findings from the previous phase in terms of the recognition participants gave to the colocation of the dental clinics, the provision of free dental services as well as the oral health promotion programmes.

[happy with the services for oral health?] Yes! I think there are more services here than down south. (Nondental care provider 1 , Interview)

Most participants mentioned the challenge of booking dental appointments due to the long waitlists. Therefore, they dreamed of promoting immediate appointment scheduling especially in cases of urgent needs. Furthermore, they wished extended oral health promotion programmes especially for the elderly and people with special needs.

Table 2 Common primary oral healthcare services in Cree communities

\begin{tabular}{|c|c|c|c|c|}
\hline $\begin{array}{l}\text { Service centre/ } \\
\text { programme }\end{array}$ & $\begin{array}{l}\text { Community } \\
\text { miyupimaatisiiun Centre }\end{array}$ & $\begin{array}{l}\text { Â Mâshkûpimâtsît } \\
\text { Awash }\end{array}$ & $\begin{array}{l}\text { Elementary school- } \\
\text { based programmes }\end{array}$ & $\begin{array}{l}\text { Daycare and } \\
\text { homecare } \\
\text { programmes }\end{array}$ \\
\hline Care providers & $\begin{array}{l}\text { Dentist } \\
\text { Dental hygienist } \\
\text { Clinical nurse } \\
\text { Dental specialist on } \\
\text { referral }\end{array}$ & $\begin{array}{l}\text { Doctor } \\
\text { Clinical nurse } \\
\text { CHR }\end{array}$ & $\begin{array}{l}\text { Nutritionist } \\
\text { Dental hygienist } \\
\text { School nurse } \\
\text { CHR } \\
\text { Dentist on referral }\end{array}$ & $\begin{array}{l}\text { Nutritionist } \\
\text { Dental hygienist } \\
\text { Home care nurse } \\
\text { CHR }\end{array}$ \\
\hline $\begin{array}{l}\text { Activities and/or } \\
\text { services }\end{array}$ & $\begin{array}{l}\text { Oral health promotion } \\
\text { Preventive dentistry } \\
\text { Restorative dentistry }\end{array}$ & Oral health promotion & $\begin{array}{l}\text { Oral health promotion } \\
\text { Preventive dentistry }\end{array}$ & $\begin{array}{l}\text { Oral health promotion } \\
\text { Preventive dentistry }\end{array}$ \\
\hline
\end{tabular}

$\mathrm{CHR}$, community health representative. 
Table 3 Contextual description of four cases

\begin{tabular}{|c|c|c|c|c|}
\hline Cases & Community 1 & Community 2 & Community 3 & Community 4 \\
\hline Population & 4033 & 5190 & 2558 & 855 \\
\hline $\begin{array}{l}\text { Geographical } \\
\text { characteristics }\end{array}$ & $\begin{array}{ll} & \text { Inland } \\
& \text { Southern }\end{array}$ & $\begin{array}{ll}- & \text { Coastal } \\
-\quad & \text { Northern } \\
& \text { Relocated }\end{array}$ & $\begin{array}{l}\text { Coastal } \\
\text { Southern }\end{array}$ & $\begin{array}{ll}> & \text { Inland } \\
& \text { Southern } \\
& \text { Relocated }\end{array}$ \\
\hline Cultural characteristics & $\begin{array}{l}\text { Traditionally live on } \\
\text { hunting, trapping and } \\
\text { fishing } \\
\text { Home of Largest } \\
\text { Fresh Water Lake } \\
\text { in Quebec, strong } \\
\text { attachment to the } \\
\text { lands }\end{array}$ & $\begin{array}{l}\text { Traditionally live on } \\
\text { hunting, trapping and } \\
\text { fishing } \\
\text { Biggest Cree } \\
\text { community located } \\
\text { on the shore of a } \\
\text { river }\end{array}$ & $\begin{array}{l}\text { Traditionally live on } \\
\text { hunting, trapping and } \\
\text { fishing } \\
\text { Oldest Cree } \\
\text { community in the } \\
\text { James Bay and an } \\
\text { important historical } \\
\text { site }\end{array}$ & $\begin{array}{l}\text { Traditionally live on } \\
\text { hunting, trapping and } \\
\text { fishing } \\
\text { Maintain a } \\
\text { harmonious } \\
\text { relationship in and } \\
\text { around a lake which } \\
\text { has plenty of fish }\end{array}$ \\
\hline $\begin{array}{l}\text { Health and oral } \\
\text { healthcare services }\end{array}$ & $\begin{array}{l}\text { CMC, dental clinic } \\
\text { within } \mathrm{CMC}\end{array}$ & $\begin{array}{l}\text { Regional hospital and } \\
\text { CMC, Dental clinic } \\
\text { within regional hospital }\end{array}$ & $\begin{array}{l}\text { CMC, dental clinic } \\
\text { within CMC }\end{array}$ & $\begin{array}{l}\mathrm{CMC} \text {, dental clinic } \\
\text { within } \mathrm{CMC}\end{array}$ \\
\hline Clinic environment & Renovated & Not renovated & Not renovated & Renovated \\
\hline $\begin{array}{l}\text { Total no of hygiene and } \\
\text { operating rooms }\end{array}$ & 8 & 4 & 2 & 3 \\
\hline No of dentists & 3 & 2 & 1 & 1 \\
\hline No of dental hygienists & 2 & 2 & 1 & 1 \\
\hline No of dental assistants & 3 & 3 & 1 & 1 \\
\hline No of dental secretaries & 2 & 2 & 1 & 1 \\
\hline $\begin{array}{l}\text { No of dental } \\
\text { consultation (2018-19) }\end{array}$ & 3745 & 2320 & 1623 & 359 \\
\hline
\end{tabular}

$\mathrm{CMC}$, Community Miyupimaatisiiun Centre.

I think there should be an improvement ... even for special needs ..., they should do at least visits because some of them are at home either \& they can't come directly here. (Non-dental care provider 2 , Interview)

Theme 2. ameliorating human resource management

Participants praised the CBHSSJB in appointing Cree healthcare workers and permanent health professionals. Appointing Cree employees reflects a cultural-appropriate way to render health services. However, they still dreamed of having more Cree and permanent employees for compensating problems associated with long waitlists for the appointment.

Cree employees make a difference. [...] When you have someone that speaks in Cree to you, you tend to listen more, you tend to ask more questions. (Administrator 5, Interview)

I wish we had more dentists so they can have regular check-ups .... I think one dentist is not enough. (Patient 1, Interview)

Theme 3: envisioning enhanced care coordination and navigation They recognised strong team working and effective coordination among professionals as the strength of this organisation. It creates a pleasant environment not only for care professionals but also for patients. Moreover, shared physical medical and dental records facilitate care coordination and referral services.

The key success of your clinic is the interaction between everybody when it works well. Here it does. [...] First of all, it's much more pleasant for me because it's a good environment to work in, but it's good for the patient as well, he can feel that things are going well, that it's pleasant. (Dental health care provider 3, Interview)

These participants hoped to strengthen the care coordination especially for chronically ill medical patients by developing more accessible protocols and guidelines for appointment scheduling and interdepartmental referral. They also desired digitalising health records for quick access to health information and streamlined health data.

It takes a long time before the report comes in, so ... by digital, It's faster. (Non-dental care provider 1, Interview)

Theme 4: organisation working towards continuous improvement Participants praised CBHSSJH's continuous efforts to develop advanced technology and infrastructure, 
Table 4 Elements of integrated primary oral healthcare across all four cases

\section{Elements of integration of oral health into primary healthcare}

\begin{tabular}{ll}
\hline Colocation & $\checkmark$ \\
Free dental services & $\checkmark$ \\
$\begin{array}{l}\text { Community-based oral } \\
\text { health promotive and } \\
\text { preventive services }\end{array}$ & $\checkmark$ \\
$\begin{array}{l}\text { Specialised services by } \\
\text { visiting specialist }\end{array}$ & $\checkmark$ \\
$\begin{array}{l}\text { Referral services outside the } \\
\text { territory }\end{array}$ & $\begin{array}{l}\text { Covered for Cree } \\
\text { beneficiaries }\end{array}$ \\
& $\begin{array}{l}\text { Patients can go via } \\
\text { Wiichihiituwin (Cree } \\
\text { Patient services) } \\
\text { department to } \\
\text { Montreal, Val d'Or } \\
\text { or Chibougamau }\end{array}$
\end{tabular}

Employment and training of All dental assistants, Local health workers (dental receptionists and assistants, dental secretaries community health and Community health workers)

\section{workers are native and} trained

Community 2
$\checkmark$
$\checkmark$
$\checkmark$

$\checkmark$

\section{Referred to Mistissini \\ or Chisasibi via \\ CHBSSJB}

- Covered for Cree beneficiaries

- Patients can go via Wiichihiituwin department to Montreal, Val d'Or or Chibougamau
- Covered for Cree beneficiaries

- Patients can go via Wiichihiituwin department to Montreal, Val d'Or or Chibougamau
Community 4

$\checkmark$

\section{$\checkmark$}

$\checkmark$

Referred to Mistissini

or Chisasibi via

CHBSSJB

- Covered for Cree beneficiaries

- Patients can go via Wiichihiituwin department to Montreal, Val d'Or or Chibougamau

\begin{tabular}{|c|c|c|c|c|}
\hline $\begin{array}{l}\text { Interprofessional } \\
\text { coordination }\end{array}$ & $\checkmark$ & $\checkmark$ & $\checkmark$ & $\checkmark$ \\
\hline $\begin{array}{l}\text { Collaboration with other } \\
\text { local organisations such as } \\
\text { Cree School Board, Youth } \\
\text { Council, Multiservice Day } \\
\text { Care Centre }\end{array}$ & $\checkmark$ & $\checkmark$ & $\checkmark$ & $\checkmark$ \\
\hline $\begin{array}{l}\text { Non-dental Staff training on } \\
\text { oral health }\end{array}$ & $x$ & $x$ & $x$ & $x$ \\
\hline $\begin{array}{l}\text { Shared physical health } \\
\text { records }\end{array}$ & $\checkmark$ & $\checkmark$ & $\checkmark$ & $\checkmark$ \\
\hline $\begin{array}{l}\text { Culturally competence } \\
\text { training }\end{array}$ & $\begin{array}{l}\text { Done for nurses, but } \\
\text { not for other health } \\
\text { providers }\end{array}$ & $\begin{array}{l}\text { Done for nurses, but } \\
\text { not for other health } \\
\text { providers }\end{array}$ & $\begin{array}{l}\text { Done for nurses, but } \\
\text { not for other health } \\
\text { providers }\end{array}$ & $\begin{array}{l}\text { Done for nurses, but } \\
\text { not for other health } \\
\text { providers }\end{array}$ \\
\hline
\end{tabular}

CHBSSJB, Cree Board of Health and Social Services of James Bay.

providing logistical support and conducting regular meetings and evaluations.

For the administration part, we have everything ... like we have more than enough ... material, ... equipment, I'm happy with what I have. (Dental care provider 4 , Interview)

Some communities have excellent infrastructure, while others are very crowded. They dreamed of new bigger infrastructure in the communities where this was not available.

We need the space; we need a new hospital. We have 3-4 chairs, actually at the moment. We have some period of time when specialist doctors come to the dental clinic. They use the same room as the dental hygienist. We need the dental hygienist that week to not provide her services. So, it's a question of space. (Administrator 6, FGD)

Theme 5: focus on integrating culture into oral healthcare

Participants appreciated the integration of traditional practices into health services by creating a specific department (Nishiiyuu Miyupimaatisiiun Department) that works on integrating traditional knowledge and culture for their health and well-being. They also valued the role 
of Cree traditional healing in health and oral health problems.

We have the cultural department now in the community ... it's only been up a couple of years now. We even have a book on traditional medicine. [...] I know one specific medicine, [....] that's been used before, ... how is tooth pain taken care of? [...] The only way I knew was feces. Feces wrapped in a cloth and put it in your tooth; then you had to bite on it. And I saw it too! it worked on my sister! [...] I know they talked about using fire ashes to brush your teeth. (Administrator 7, interview)

They praised non-Cree health professionals' interest in learning culture with their own experiences working in Eeyou Istchee. Non-Cree employees even pointed out more relevance of immersing in the Cree culture than getting trained on the culture. These non-Cree employees while dealing with Cree clients, emphasised learning Cree history and sharing their experiences with the elders in the communities to better understand their clients.

(If) you understand the culture, easier your work is. At the beginning, it was so hard because we take all our knowledge from the south ... and we try to apply them here, and [...], it doesn't help. Experience, you have to come, and ... because those things cannot be taught, you need to live with people to realize. (Dental care provider 4 , interview)

The non-judgment of the patient is that we will learn to have more openness to cultural differences...; then it's sure that after listening, you have to know the history of the Cree [...] You have to know what they lived. [...] Then there are times when I do not understand what's going on with the client, ... I go to sit down with social services, and then I say there's something I do not understand, is that what Can you explain to me? Then they will not give you the answer right now, they will give you a big history before. Then, there are lots of times I've been stuck, and then I go to ... the elder in social services, I need help there, I'm stuck, you explain to me and in general, I'll have feedback, okay, that's why this person is like that because culturally you do not say it, it's unsaid, but that's what happened. (Non-dental care provider 3, Interview)

However, they wished to raise community awareness about traditional medicines and to integrate cultural oral health practices by learning about traditional healing from elders. This will not only help in keeping their traditional Cree healing alive but also will be beneficial in achieving holistic health.

Some of our elders ... can help fix the toothache or can fix health, a lot of stuff with traditional medicine, AMAZING! ... Respect what we know because it's something that's really amazing ... [we need] to integrate all the knowledge ... from the elders. (Nondental care provider 4, Interview)

People need to be shown ... how to work with the [traditional] medicines and ... educating them would be a vital thing for the community ... that's what I think needs to be done. (Administrator 7, Interview)

\section{Design phase}

Recommendations for an action plan were discussed and validated with key collaborators and were presented to administrators and healthcare providers. These recommendations were divided into the following categories: increasing promotive and preventive services, faster access to dental services, improving management, better coordination, and promoting cultural integration. (table 5).

\section{DISCUSSION}

To our knowledge, this is the first study that uses AI in the field of Indigenous oral health research. The use of AI in evaluation allows for better recognition of Indigenous culture and values in organisational health services. Our results suggest that the CBHSSJB has developed a grassroots innovation in integrating POHC. Commencing with the identification of oral health needs in the communities, this organisation is progressively working on the regular development of policies for organisational governance, management and the coordination of services. The recommendations derived from the results can help to optimise the integrated POHC services in the CBHSSJB organisation. Also, these recommendations will help in providing new scientific evidence on the integration of oral health into primary care, which could be instrumental in improving the quality of oral healthcare.

Facilitators of integrated oral healthcare are similar to those identified in previous studies, such as interprofessional collaboration, geographical proximity, shared health records, supportive operational policies and native health workers. ${ }^{35} 36$ Similarly, barriers in this regard were also in line with what has been identified in previous literature; for example, lack of exclusive bidirectional interprofessional education, lack of human resources and staff turnover. ${ }^{35}$

In general, there are few integrated health programmes such as Medicaid, Affordable Care Act, CareMore health systems that offer dental coverage; most of them have very limited or only emergency based dental coverage especially for vulnerable populations. ${ }^{3738}$ Several organisations and associations including Neighborcare, Dorchester House Multiservice Centre, Kaiser Permanente, Marshfield Clinic, Boston Medical Centre have used novel ideas to integrate oral healthcare into primary care, such as colocation, cross-referral process, cross-training on oral health screening for physicians oral healthcare screening in schools, interprofessional collaboration, shared electronic health records, case management and performance measurement. ${ }^{36-40}$ The CBHSSJB is actually addressing most of the recommendations for developing 
Table 5 Recommendations developed and validated in design phase

\section{Expanding promotion of oral healthcare}

- Extending oral health promotion and prevention to all age groups.

- For children and families: Involvement of social workers and community workers in oral health promotion for families; involving young parents in oral health promotion; Full-time dental hygienist or at least more frequent dental hygienist rotation for AWASH, to introduce oral health promotion into school curriculum.

- For elders and people with special needs: Integration of home-based oral healthcare; expanding oral health promotion and prevention at multiservice day centres.

- Recognising and engaging 'community innovators' such as elders, youths, local community leaders for oral health promotion.

- Facilitating oral health prevention and promotion in public health programmes and community activities such as oral health nights, parents' nights, sports events, festivals, cultural activities; provision of dental weeks or dental day; raising competitive behaviour by organising competitions like 'beautiful teeth'.

- Promotion via audio-visual aids and information technologies such as pamphlets, flyers and posters, radio, local monthly newsletter, social media websites, creating promotion videos (in Cree language especially for elders), conducting workshops and presentations.

- Provision of mobile dental vans for promotion and services for people with limited accessibility.

- Provision of tele-oral health services by engaging native care providers.

\section{Facilitating access to care}

- Regular dental check-up especially for people at risk such as those with chronic illnesses.

- Extending hours of work such as weekend clinics, evening clinics to assure better services for working adults and younger population.

- Emergency walk-in at dental clinic during weekends and holidays.

- Provision of more frequent specialised services in all the communities.

3. Augmenting organisational management

- Reinforcement of recruitment of additional and permanent oral healthcare providers by offering financial and non-financial benefits.

- Custom training of local/ Indigenous people to become professional healthcare providers.

- Regular training, continuing education and workshops for dental primary care providers including dental assistants, secretaries, CHRs.

- Infrastructural developments.

Strengthening care -coordination
Development of uniform protocol for appointment scheduling.
Strengthening protocols for better care coordination.
Developing a case management system by appointing case manager for every patient.
Oral healthcare training for non-dental primary care providers such as dental triage training.
Promoting cultural integration
- Eroposing a new job position of 'Dental CHR'.
Engaging the Cree communities and elders to collaborate in the development of a Cree language dental
glossary to help improve communication.
Researching and adopting traditional practices related to oral health as well as acknowledging elders'
experiences.
Development of specific cultural competency training for non-Indigenous healthcare professionals.
- Educating community people on the role of traditional medicine.
- Having Sign Boards at CMC in the Cree language particularly for elders.

$\mathrm{CHR}$, community health representative; $\mathrm{CMC}$, Community Miyupimaatisiiun Centre.

an integrated POHC approach from available evidence of various organisations. ${ }^{79}$ For instance, it established a population-based health management approach, shared health records, assured geographical proximity, had dental coverage, interprofessional collaboration and referral. ${ }^{39}$

The themes derived from this study coincide with all the dimensions of integrated care as per the Rainbow model and the five foundations of integrated care model. As reported by Leutz, the degree of integrated
POHC at the CBHSSJB corresponds to the coordination and linkage rather than full integration. ${ }^{41}$ Based on the extent of integration of dental care described by Atchison $e t a l$, the CBHSSJB represents an example of co-location and closer integration of medical and dental providers. ${ }^{36}$

The selection of four cases represents a reasonable number to achieve diversity among the key variables as well as the transferability of our findings. The diverse roles and responsibilities of the study participants support 
the applicability of these findings among the stakeholders of different healthcare organisations. However, this study might have encountered bias due to various types of study participants such as administrators, healthcare providers and patients. Nevertheless, a large sample size would have outweighed such biases by ensuring representativeness from all participants' range. Being qualitative in nature, this study does not support the generalisability of its findings; however, our study findings contribute to integrated POHC research and can be applicable to other similar settings.

\section{CONCLUSION}

This study results suggest that the CBHSSJB has developed a grassroots innovation in integrating POHC. This organisation has been successful in implementing strategic planning on oral health integration into primary care at all levels of integration, nonetheless, the organisation needs further strengthening for full integration.

Acknowledgements We would like to acknowledge the Cree Board of Health and Social Services of James Bay, Cree communities and research team members for their constant help and support. The authors gratefully acknowledge the administrators, healthcare providers and patients that participated in this study. We are thankful to Lucie Papineau, Evelyne Lefebvre and Nicole Jolin for their continuous support, valuable suggestions and worthy contributions.

Contributors RS contributed to study conception, design, data collection, transcription, reviewing transcripts, coding, analysis, interpretation of data and manuscript writing. YC participated in study conception, data collection, data interpretation and critical revision of the manuscript. FG contributed to data collection, data interpretation and critical revision of the manuscript. CB and MEM were engaged in data interpretation and critical revision of the manuscript. JT contributed to study concept and design, data interpretation and critical revision of the manuscript. EE contributed to study concept and design, project administration, data collection, data analysis, data interpretation, manuscript drafting and critical revision of manuscript. All authors gave their final approval and agreed to be accountable for all aspects of the work.

Funding This study was supported by the funding from the Canadian Institutes of Health Research (grant number: Gl1-145123). It has been cofunded by the Institut de recherche en santé publique de l'Université de Montréal, Quebec Population Health Research Network, the Network for Canadian Oral Health Research, the Network for Oral and Bone Health Research and Fondation de l'Ordre des dentistes du Québec. RS is a doctorate student funded by the merit scholarship programme for foreign students (PBEEE) by the Fonds de recherche du Québec - Nature et technologies.

Competing interests None declared.

Patient consent for publication Not required.

Ethics approval The ethical approval for this study was obtained from the Institutional ethics review board of the Université de Montréal (15-130-CERES-P), McGill University (A10-B39-18A) and research committee of Cree Board of Health and Social Services of James Bay.

Provenance and peer review Not commissioned; externally peer reviewed.

Data availability statement Data are available on reasonable request. All data relevant to the study are included in the article or uploaded as online supplementary information. The datasets generated and analysed during the current study are available from the corresponding author on reasonable request.

Open access This is an open access article distributed in accordance with the Creative Commons Attribution Non Commercial (CC BY-NC 4.0) license, which permits others to distribute, remix, adapt, build upon this work non-commercially, and license their derivative works on different terms, provided the original work is properly cited, appropriate credit is given, any changes made indicated, and the use is non-commercial. See: http://creativecommons.org/licenses/by-nc/4.0/.
ORCID iD

Elham Emami http://orcid.org/0000-0002-7730-4139

\section{REFERENCES}

1 The First Nations Information Governance Centre. Report on the findings of the first nations oral health survey (FNOHS) 2009-10. Ottawa, ON: The First Nations Information Governance Centre, 2012.

2 Ministry of Health. Our oral health: key findings of the 2009 New Zealand oral health survey. Wellington, NZ: Ministry of Health, 2010.

3 Jamieson L, Armfield J, Roberts-Thomson K, Australian Institute of Health and Welfare, Dental Statistics and Research Unit. Oral health of Aboriginal and Torres Strait Islander children. AlHW cat. No. den 167. (dental statistics and research series No. 35). Canberra: Australian Institute of Health and Welfare, 2007.

4 Phipps K, Ricks T. The oral health of American Indian and Alaska native adult dental patients: results of the 2015 IHS oral health survey. Indian health service data brief. Rockville, MD: Indian Health Service, 2016.

5 Reading C, Wien F. Health inequalities and social determinants of Aboriginal people' health. Prince George, BC, Canada: National Collaborating Centre for Aboriginal Health, 2009.

6 Wilk P, Cooke M, Stranges S, et al. Reducing health disparities among Indigenous populations: the role of collaborative approaches to improve public health systems. Int J Public Health 2018;63:1-2.

7 U.S. Department of Health and Human Services: Oral Health Coordinating Committee. U.S. department of health and human services oral health strategic framework, 2014-2017. Public Health Rep 2016;131:242-57.

8 Petersen PE. The world oral health report 2003: continuous improvement of oral health in the 21st century: the approach of the who global oral health programme.Geneva, Switzerland: World Health Organization, 2003: 3-24.

9 van Raak A, Mur-Veeman I, Hardy B, et al. Integrated care in Europe: description and comparison of integrated care in six EU countries. Maarssen, the Netherlands: Elsevier gezondheidszorg, 2003.

10 Isman RE. Integrating primary oral health care into primary care. $J$ Dent Educ 1993;57:846-52.

11 Cree Board of Health and Social Services of James Bay. Strategic regional plan to improve health and social services "Miyupimaatisiiun" - "Building a Strong and Healthy Cree Nation". Chisasibi, QC: Cree Board of Health and Social Services of James Bay, 2004.

12 Emami E, Couturier Y, Girard F, et al. Integration of oral health into primary health care organization in Cree communities: a workshop summary. J Can Dent Assoc 2016;82:g30.

13 Grand Council of the Crees (Eeyou Istchee) / Cree Nation Government. Community \& Culture: An overview of the eastern coast and inland lowlands of James Bay. Nemaska; QC: Grand Council of the Crees / Cree Nation Government. Available: https://www.cngov. $\mathrm{ca}$ [Accessed 12 Jun 2019].

14 Cree Board of Health and Social Services of James Bay. Strategic regional plan- Striving to achieve Nishiiyuu Miyupimaatisiiun together 2016-2021. Chisasibi, QC: Cree Board of Health and Social Services of James Bay, 2017.

15 Harnagea H, Lamothe L, Couturier Y, et al. From theoretical concepts to policies and applied programmes: the landscape of integration of oral health in primary care. BMC Oral Health 2018;18:23.

16 Watkins JM, Mohr B, Kelly R, eds. Appreciative Inquiry: Change at the speed of imagination. San Francisco, CA: John Wiley and Sons, Inc, 2001.

17 Emami E, Torrie JE, Couturier $\mathrm{Y}$, et al. Oral health integrated into primary care: Participatory evaluation of implementation and performance in Quebec Cree communities. Operating Grant: Population Health Intervention Research - Pathways: Canadian Institutes of Health Research, 2016. Available: http://webapps.cihrirsc.gc.ca/decisions/p/project_details.html?applld=343763\&lang=en [Accessed 10 Sep 2019].

18 O'Brien BC, Harris IB, Beckman TJ, et al. Standards for reporting qualitative research: a synthesis of recommendations. Acad Med 2014;89:1245-51.

19 First Nations Information Governance Centre (FNIGC). Ownership, control, access and possession (OCAP'M): the path to first nations information governance. Ottawa, ON: First Nations Information Governance Centre, 2014.

20 Cree Board of Health and Social Services of James Bay. Cree health. Chisasibi, QC: Cree Board of Health and Social Services of James Bay, 2012. Available: http://www.creehealth.org/ [Accessed 12 Jan 2018]. 
21 Cree Board of Health and Social Services of James Bay. Annual report of the Cree board of health and social services of James Bay, 2017-18. Chisasibi, QC: Cree Board of Health and Social Services of James Bay, 2018.

22 Yin RK. Case study research: design and methods. Thousand Oaks, CA: SAGE publications, Inc, 2014.

23 Patton M. Developmental evaluation: applying complexity concepts to enhance innovation and use. New York: Guilford, 2011.

24 Laycock A, Bailie J, Matthews V, et al. A developmental evaluation to enhance stakeholder engagement in a wide-scale interactive project disseminating quality improvement data: study protocol for a mixedmethods study. BMJ Open 2017;7:e016341.

25 Dunlap CA. Effective evaluation through appreciative inquiry. Perf Improv 2008;47:23-9.

26 Trajkovski S, Schmied V, Vickers M, et al. Using appreciative inquiry to transform health care. Contemp Nurse 2013;45:95-100.

27 Preskill H, Catsambas TT. Reframing evaluation through Appreciative inquiry. Thousand Oaks, CA: Sage Publishication, Inc, 2006.

28 Canadian Nurses Association, Canadian Medical Association, Health Action Lobby. Integration: a new direction for Canadian health care. A report on the health provider Summit process, 2013. Available: https://www.cna-aiic.ca/ /media/cna/files/en/cna_cma_ heal_provider_summit_transformation_to_integrated_care_e.pdf [Accessed 22 Oct 2018]

29 Bowen GA. Document analysis as a qualitative research method. Qualitative Research Journal 2009;9:27-40.

30 Patton MQ. Qualitative research \& evaluation methods: Integrating theory and practice. 4 ed. Thousand Oaks, CA: SAGE Publications, Inc, 2015.

31 Valentijn PP. Rainbow of chaos- $A$ study into the theory and practice of integrated primary care [Doctoral thesis. Tilburg University, The Netherlands, 2015
32 Miles MB, Huberman AM. Qualitative data analysis: an expanded source. 2nd ed. Thousand Oaks, CA: Sage Publications, Inc, 1994.

33 Carter CA, Ruhe MC, Weyer S, et al. An appreciative inquiry approach to practice improvement and transformative change in health care settings. Qual Manag Health Care 2007;16:194-204.

34 Ryan GW, Bernard HR. Data management and analysis methods. In: Denzin NK, Lincoln YS, eds. The SAGE Handbook of qualitative research. Thousand Oaks, CA: Sage Publications, Inc, 2000.

35 Harnagea $\mathrm{H}$, Couturier $\mathrm{Y}$, Shrivastava R, et al. Barriers and facilitators in the integration of oral health into primary care: a scoping review. BMJ Open 2017;7:e016078.

36 Atchison KA, Weintraub JA. Integrating oral health and primary care in the changing health care landscape. $N C$ Med $J$ 2017;78:406-9.

37 Hostetter M, Kelin S. In focus: integrating oral health into primary care. New York, NY: The Commonwealth Fund, 2015. https://www. commonwealthfund.org/publications/newsletter-article/2015/feb/ focus-integrating-oral-health-primary-care

38 Powers B, Donoff B, Jain SH. Bridging the dental divide: overcoming barriers to integrating oral health and primary care. Health Affairs Blog 2017.

39 Brownlee B. White paper - Oral health integration in the patientcentered medical home (PCMH) environment: Case studies from community health centers. Seattle, WA: Qualis Health, 2012.

40 Kaufman LB, Henshaw MM, Brown BP, et al. Oral health and interprofessional collaborative practice: examples of the team approach to geriatric care. Dent Clin North Am 2016:60:879-90.

41 Leutz WN. Five laws for integrating medical and social services: lessons from the United States and the United Kingdom. Milbank $Q$ 1999;77:77-110. 